\title{
KAEDAH MUAFAKAT DALAM PEMBAHAGIAN HARTA PUSAKA ORANG ISLAM: KAJIAN DI MAHKAMAH TINGGI SYARIAH NEGARA BRUNEI DARUSSALAM
}

\section{Consensual Agreement Method in Muslim Estate Distribution: A Study in the Shariah High Court Brunei Darussalam}

\author{
Mohammad Arif Sabtu \\ Master Candidate, Department of Shariah and Law, \\ Academy of Islamic Studies, \\ University of Malaya, 50603 Kuala Lumpur. \\ aref.hs@siswa.um.edu.my \\ Siti Mashitoh Mahamood \\ Associate Professor, Department of Shariah and Law, \\ Academy of Islamic Studies, \\ University of Malaya, 50603 Kuala Lumpur. \\ mas68@um.edu.my
}

\begin{abstract}
The mentality of accepting farā'id mandatorily, followed by the shallow knowledge of Islamic inheritance law, plus intolerance of fellow heirs in solving the problem of inherited wealth are often being the major factors of some inheritance cases be difficult and delayed to be solved. This issue actually can be solved if Muslims, particularly the heirs involved understand the concept of inheritance law including the concensus method, known as "takhāruj" which means withdrawing to accept the inheritance wealth either a part of it or all by giving it to other heirs either by compensation or without compensation. This concept does not violate the legal provision as advocated by Islamic law of inheritance as long as it is achieved through consent without any coercion or undue influence. In fact, this concept provides the very ideal and the best way to the heirs in solving the problem
\end{abstract}


of distribution of inheritance in a amicable way. The objective of this research is to examine the administrative procedures among Muslim estate distribution in Brunei Darussalam. Next, to review the mechanisms applied in the concept of consensus of heirloom estate. It also aims to identify methods of solution applied as to consensual agreement method either in line and accordance with the concept of Islam or vice versa.

Keywords: Islamic inheritance, farā'id, consensual method, takhāruj

\section{PENDAHULUAN}

Dalam menyelesaikan pembahagian harta pusaka orang Islam, mekanisme yang dianjurkan adalah dengan mengguna pakai kaedah faraid. Ini kerana faraid adalah sesuatu yang telah ditetapkan oleh Allah SWT kepada setiap hambanya untuk mengurus harta pusaka. Meskipun begitu, terdapat juga mekanisme lain yang sering diaplikasikan sebagai solusi dalam menyelesaikan masalah agihan harta pusaka. Mekanisme ini dinamakan mekanisme permuafakatan atau lebih dikenali sebagai kaedah takhāruj (Abdul Rashid Hj. Abdul Latif, 1997: 162166; Mohd Zamro Muda \& Mohd. Ridzuan Awang, 2006: 176-180; Ahmad Hidayat Buang, 2007: 315-318). Kaedah ini juga merupakan șulh sesama ahli waris kerana ianya dilakukan berasaskan kepada prinsip redha meredhai, persetujuan (Mohd Zamro Muda \& Mohd. Ridzuan Awang, 2006: 180) dan toleransi.

Sering berlaku dalam kalangan masyarakat kita hari ini, terdapat di antara waris-waris menarik diri dari menerima harta waris dan menolak harta tersebut kepada ahli waris yang lain. Situasi sebegini selalunya berlaku antara ahli keluarga terdekat seperti ibu atau bapa menolak bahagian mereka dan menyerahkannya kepada anak atau cucu dan seumpamanya. Penolakan atau penarikan diri seperti ini dibenarkan oleh syara' mengikut konsep takhāruj. Dengan adanya kaedah seperti ini, ianya dapat menyangkal pendapat dan momokan serta mentaliti sesetengah pihak yang mengatakan bahawa harta pusaka wajib diambil atau diterima mengikut faraid secara mandatori.

Islam mengiktiraf alternatif pembahagian seperti ini kerana ianya dilihat menepati ciri-ciri keadilan dalam Islam dan mampu mencapai matlamat pembahagian pusaka sebenar selagi mana ianya tidak bercanggah dengan syariat. Malah, kaedah ini sebenarnya memberi peluang kepada setiap ahli waris untuk memilih cara yang terbaik dalam menyelesaikan permasalahan pembahagian harta pusaka. 


\section{UNDANG-UNDANG DAN PENTADBIRAN HARTA PUSAKA ORANG ISLAM DI NEGARA BRUNEI DARUSSALAM}

\section{Undang-Undang Harta Pusaka Orang Islam di Negara Brunei Darussalam}

Sehingga ke hari ini, Negara Brunei Darussalam belum mempunyai sebarang undang-undang bertulis khusus mengenai undang-undang pusaka. Peruntukan yang berhubung dengan undang-undang pusaka dan wasiat orang Islam adalah tertakluk di bawah bidang kuasa dan pentadbiran Mahkamah Syariah. Oleh itu, berhubung dengan pengurusan dan pentadbiran harta pusaka orang Islam di Brunei Darussalam, adalah menjadi tanggungjawab dan bidang kuasa Mahkamah Tinggi Syariah Negara Brunei Darussalam untuk menguruskan hal ehwal perwarisan orang Islam di negara tersebut berdasarkan peruntukan yang diberikan terhadap Mahkamah Tinggi Syariah Negara Brunei Darussalam melalui Bab 15(b) Akta Mahkamah-Mahkamah Syariah (Penggal 184) yang memperuntukkan:

"15. Mahkamah Tinggi Syariah hendaklah-

(a) ...; dan

(b) Dalam bidang kuasa malnya, mendengar dan memutuskan semua tindakan dan prosiding yang berhubung dengan-

(viii) Pembahagian dan pewarisan harta, berwasiat atau tidak berwasiat;

(ix) Penentuan orang-orang yang berhak mendapat semua atau mana-mana bahagian dari harta pusaka si-mati Islam dan bahagian-bahagiannya yang orang-orang itu masing-masing berhak; atau"

Dengan adanya peruntukan ini, maka penentuan bagi orang-orang yang berhak mendapat bahagian daripada harta pusaka adalah terletak di bawah bidang kuasa mal Mahkamah Tinggi Syariah. Sungguhpun demikian, pada masa ini Mahkamah Tinggi Syariah hanyalah bertindak dalam menentukan orang-orang yang berhak dan membuat kadar bahagian mengikut kiraan faraid dengan mengeluarkan satu sijil faraid sahaja. Di sini jelas menunjukkan bahawa bidang kuasa Mahkamah Syariah ternyata amat terhad dan tidaklah sampai kepada tahap memutuskan perkara berkaitan harta pusaka itu. Ianya hanya tertumpu kepada penentuan kadar bahagian setiap ahli waris.

Perlu diingatkan bahawa undang-undang Brunei Darussalam iaitu Akta Probet dan Pentadbiran Penggal 11 menghendaki tuntutan dibuat kepada 
Pegawai Waris, Pejabat Kehakiman sebelum pembahagian ke atas sebarang tindakan dibuat terhadap harta pusaka tersebut. Berdasarkan peruntukan dari Akta berkenaan harta pusaka orang Islam hendaklah dirujuk kepada Unit Waris Mahkamah Tinggi Syariah bagi menentukan bahagian yang berhak kepada ahli waris dan mengesahkan ahli waris yang layak menjadi pentadbir kepada harta si mati. Perkara ini jelas disebutkan dalam Seksyen 71 daripada Akta Probet dan Pentadbiran:

"Wherever the Probate Officer is required by this act in accordance with Muslim law is practised in Brunei or to act with the advice of the Religious Council he shall refer the matter to the Court of the Chief Kadi and shall act upon any written statement which is certified by that court to have been obtained for the purpose of the matter so reffered in accordance with section 50 of the Religious Council and Kadis Court Act" 1

Ini bererti, pentadbiran undang-undang perwarisan masih lagi di bawah kawalan dan bidang kuasa Mahkamah Besar di bawah peruntukan Akta Probet dan Pentadbiran. Ini termasuklah bagi harta orang Islam mahupun bukan Islam. Hal ini berlaku disebabkan ketiadaan peruntukan yang jelas dan penafsiran yang berbagai-bagai. Bersabit daripada perkara ini, maka timbullah pertindihan bidang kuasa dalam melaksanakan beberapa peruntukan yang telah dikuatkuasakan.

Walaupun Brunei setakat ini belum mempunyai undang-undang khusus mengenai harta pusaka, namun demikian, ketiadaan undang-undang substantif ini sama sekali tidak menjejaskan atau menghadkan kuasa Mahkamah Tinggi Syariah yang telah diberikan dengan nyata di bawah bab (15) (viii) dan (ix). ${ }^{2}$ Bermakna, peruntukan ini hendaklah dibaca bersama dengan bab 5 dan bab 6 (1) dari Akta yang sama yang jelas menyatakan: ${ }^{3}$

"5. Bagi mengelakkan sebarang keraguan, adalah dengan ini diisytiharkan bahawa tiada mahkamah selain dari sesebuah mahkamah yang ditubuhkan di bawah Bahagian II boleh mendengar atau memutuskan apa-apa tuntutan atau prosiding di bawah bidang kuasa Mahkamah-Mahkamah Syariah.”

"6.(1) Adalah dengan ini ditubuhkan Mahkamah-Mahkamah Syariah yang terdiri daripada Mahkamah-Mahkamah Rendah

\footnotetext{
$1 \quad$ Akta Probet dan Pentadbiran 1984, Penggal 11.

2 Kartini Abdullah (Pendaftar Mahkamah Tinggi Syariah, Negara Brunei Darussalam), dalam temu bual dengan penulis, pada 16 Jun 2015.

3 Akta Mahkamah-Mahkamah Syariah, Penggal 184.
} 
Syariah, Mahkamah Tinggi Syariah and Mahkamah Rayuan Syariah, dengan bidang kuasa, kuasa-kuasa, kewajipan dan autoriti sebagaimana yang diberi dan dikenakan oleh Perintah ini dan oleh sebarang undang-undang bertulis yang lain."

Dalam peruntukan Bab 15(b) (viii) dan (ix) dari Akta MahkamahMahkamah Syariah Penggal 184 jelas memberikan Mahkamah Tinggi Syariah bidang kuasa dalam membuat penentuan dan pembahagian harta pusaka si mati Islam sama ada bagi jenis harta alih ataupun harta tak alih. Kerana peruntukan itu besifat umum. Tetapi realitinya, Mahkamah Tinggi Syariah hanya melaksanakan penentuan dan pembahagian bagi satu jenis harta pusaka sahaja iaitu harta tak alih seperti tanah atau tukar milik perumahan berdasarkan penentuan bahagian sama ada mengikut pembahagian hukum syarak, yang dikeluarkan melalui sijil faraid atau persetujuan ahli-ahli waris untuk membuat pembahagian sama rata atau ada sebahagian ahli waris menyerahkan kepada ahli waris yang lain atau mengikut kehendak ahli waris atas dasar permuafakatan bersama.

\section{Badan Pengendali Harta Pusaka Orang Islam di Negara Brunei Darussalam}

Terdapat beberapa badan atau institusi yang perlu dirujuk dalam mengurus tadbir pembahagian harta pusaka orang Islam di Brunei Darussalam mengikut kategori atau jenis harta pusaka yang ditinggalkan. Secara ringkasnya adalah seperti jadual dibawah:

Jadual 1: Badan Pengendali Harta Pusaka Orang Islam Mengikut Kategori Harta Pusaka

\begin{tabular}{cc}
\hline \multicolumn{3}{c}{ Kategori / Jenis Harta } \\
\hline Alih & Tak Alih
\end{tabular}

\begin{tabular}{|c|c|c|}
\hline \multirow{6}{*}{ 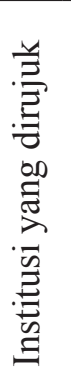 } & Mahkamah Besar (Supreme Court) & Mahkamah Besar (Supreme Court) \\
\hline & Mahkamah Tinggi Syariah & Mahkamah Tinggi Syariah \\
\hline & Jabatan Pengangkutan Darat & Jabatan Tanah \\
\hline & Jabatan Perbendaharaan & Jabatan Kemajuan Perumahan \\
\hline & Tabung Amanah Pekerja (T.A.P) & \\
\hline & Pihak Bank / Syarikat insuran & \\
\hline
\end{tabular}

Sumber: Hasil Penyelidikan Penulis. 


\section{KAEDAH PEMBAHAGIAN DAN AMALAN MUAFAKAT DALAM AGIHAN HARTA PUSAKA TAK ALIH ORANG ISLAM DAERAH BRUNEI MUARA YANG DILAKUKAN DI MAHKAMAH TINGGI SYARIAH NEGARA BRUNEI DARUSSALAM}

Umumnya, terdapat dua bentuk kaedah pembahagian harta pusaka tak alih yang berupa tanah dan perumahan yang diamalkan oleh masyarakat Islam Daerah Brunei Muara. Dua kaedah tersebut ialah kaedah faraid dan permuafakatan bersama antara ahli waris.

Dalam menganalisis kaedah pembahagian pusaka tak alih masyarakat Islam Daerah Brunei Muara, penulis telah membuat satu analisis mudah ke atas keskes tuntutan pembahagian yang dilakukan di Unit Waris Mahkamah Tinggi Syariah Brunei Darussalam. Analisis ini hanya melibatkan harta tak alih orang Islam yang berupa tanah dan rumah bagi penduduk muslim di Daerah Brunei Muara sahaja. Tujuannya ialah untuk melihat sejauhmana kaedah muafakat dalam menyelesaikan urusan pembahagian harta pusaka diamalkan oleh masyarakat Islam di daerah ini serta meninjau bagaimana pengaplikasiannya.

Sejumlah 753 kes tuntutan pembahagian telah dipilih untuk dianalisis. Daripada jumlah tersebut, sebanyak 693 kes merupakan kes tuntutan tanah dan selebihnya iaitu sebanyak 60 kes melibatkan kes tuntutan tukar milik perumahan. Kesemua kes adalah kes yang telah didaftarkan di Unit Waris Mahkamah Tinggi Syariah bagi tempoh lima tahun kebelakangan, iaitu dari tahun 2010 hingga 2014.

Jadual 2: Statistik Permohonan Daerah Brunei Muara Bagi Tuntutan Tanah Waris Dan Tukar Milik Perumahan Yang Dihadapkan Ke Unit Waris Mahkamah Tinggi Syariah Brunei Darussalam Dari Tahun 2010-2014

\begin{tabular}{cccc}
\hline Tahun & $\begin{array}{c}\text { Tuntutan } \\
\text { Tanah Waris }\end{array}$ & $\begin{array}{c}\text { Tuntutan } \\
\text { Perumahan }\end{array}$ & Jumlah \\
\hline 2010 & 135 & 12 & 147 \\
2011 & 159 & 19 & 178 \\
2012 & 143 & 11 & 154 \\
2013 & 119 & 13 & 132 \\
2014 & 137 & 5 & 142 \\
\hline Jumlah & $\mathbf{6 9 3}$ & $\mathbf{6 0}$ & $\mathbf{7 5 3}$ \\
\hline
\end{tabular}

Sumber: Bahagian Penyelidikan, Mahkamah Rayuan Syariah. 


\section{Analisis Kaedah Pembahagian Secara Muafakat Ke Atas Tanah}

Sebanyak 693 kes tuntutan tanah waris telah dianalisis oleh penulis bagi kes lima tahun kebelakangan iaitu dari tahun 2010 hingga 2014. Hasil analisis yang dijalankan menunjukkan bahawa masyarakat Islam Daerah Brunei Muara lebih cenderung memilih kaedah permuafakatan dalam menyelesaikan permasalahan pembahagian tanah waris. Kajian mendapati pemilihan kaedah faraid dalam menyelesaikan urusan pembahagian harta pusaka adalah terlalu kecil jika dibandingkan dengan kaedah muafakat atau persetujuan bersama. Jadual di bawah memperlihatkan jurang perbezaan antara ke dua jenis kaedah yang digunakan terhadap tuntutan tanah.

Jadual 3: Analisis Kaedah Pembahagian Pusaka Bagi Kes Tuntutan Tanah Daerah Brunei Muara Bagi Tahun 2010-2014

\begin{tabular}{cccc}
\hline & & \multicolumn{2}{c}{ Kaedah Pembahagian } \\
\cline { 3 - 4 } Tahun & Jumlah Kes & Faraid & Muafakat \\
\hline 2010 & $134(100 \%)$ & $17(12.69 \%)$ & $117(87.31 \%)$ \\
2011 & $159(100 \%)$ & $10(06.30 \%)$ & $149(93.70 \%)$ \\
2012 & $143(100 \%)$ & $20(14.00 \%)$ & $123(86.00 \%)$ \\
2013 & $119(100 \%)$ & $12(10.10 \%)$ & $107(89.90 \%)$ \\
2014 & $138(100 \%)$ & $12(08.70 \%)$ & $126(91.30 \%)$ \\
\hline Jumlah/ & $\mathbf{6 9 3}$ kes & $\mathbf{7 1 ~ k e s}$ & $\mathbf{6 2 2} \mathbf{k e s}$ \\
Purata & $\mathbf{( 1 0 0 \% )}$ & $\mathbf{( 1 0 . 2 5 \% )}$ & $\mathbf{( 8 9 . 7 5 \% )}$ \\
\hline
\end{tabular}

Sumber: Hasil Penyelidikan Penulis.

Jadual di atas menunjukkan bahawa masyarakat Islam setempat lebih gemar memilih kaedah muafakat dalam pembahagian harta pusaka. Sebanyak 89.75 peratus (622 kes) memilih kaedah muafakat berbanding 10.25 peratus (71 kes) memilih kaedah faraid. Bermakna pembahagian harta pusaka dalam kalangan masyarakat Islam Daerah Brunei Muara melalui kaedah muafakat amat meluas pengaplikasiannya.

Dalam mengaplikasikan kaedah muafakat tersebut, terdapat beberapa mekanisme pembahagian yang turut digunakan. Daripada sejumlah 622 kes $(89.75 \%)$ yang diselesaikan dengan kaedah muafakat itu, sebanyak 428 kes $(61.76 \%)$ diselesaikan secara serah hak sama ada harta tersebut diserahkan kepada salah seorang ahli waris atau menyerahkan harta tersebut kepada waris-waris lain. 
Manakala sebanyak 16 kes (2.31\%) dibahagikan dengan kadar sama rata antara ahli waris tanpa mengira jantina waris tersebut. 178 kes $(25.7 \%)$ pula diselesaikan mengikut kaedah campuran antara faraid, serah hak dan berbagi sama rata.

Rajah 4: Pecahan Cara Penyelesaian Tuntutan Tanah Waris Daerah Brunei Muara Bagi Tahun 2010-2014 di Unit Waris Mahkamah Tinggi Syariah

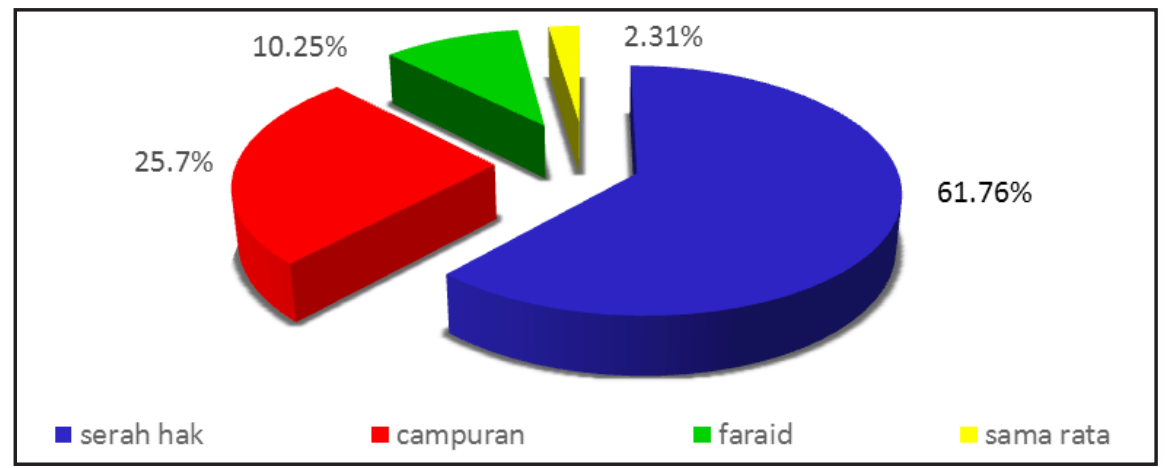

Sumber: Hasil Penyelidikan Penulis.

Secara tuntasnya, mekanisme kaedah muafakat yang paling dominan yang banyak digunakan oleh masyarakat Islam Daerah Brunei Muara dalam agihan harta pusaka yang berupa tanah ialah dengan mengaplikasikan mekanisme serah hak kepada ahli waris lain secara percuma tanpa sebarang gantian atau imbalan di mana lebih daripada separuh kes diselesaikan dengan cara ini. Tiada sebarang ganti rugi yang dikemukakan oleh ahli waris yang menggunakan mekanisme kaedah permuafakatan ini.

Namun demikian, penulis tidak menafikan bahawa terdapat kemungkinan ada dalam kalangan mereka menerima bayaran ganti rugi yang tertentu melalui rundingan luar dan tidak direkodkan. Menurut pandangan penulis, sekiranya bayaran ganti rugi tersebut dibuat, ianya tidaklah lebih daripada sebuah pemberian ehsan daripada waris tersebut. Walau bagaimanapun, penulis menyarankan agar mana-mana kes yang mengemukakan ganti rugi, seelok-eloknya direkodkan ke dalam fail mahkamah. Ini adalah bertujuan bagi mengelakkan konflik dan supaya tidak menjadi perkara berbangkit di kemudian hari.

Penulis juga tidak menolak terdapat kemungkinan besar masyarakat Islam setempat tidak mengetahui asas-asas kaedah takhāruj yang membolehkan mereka meminta ganti rugi terhadap harta tanah yang dilepaskan kepada ahli waris lain. Oleh itu, usaha untuk menyebarluaskan tentang perkara ini amat perlu dilakukan. 
Bagi mekanisme pembahagian secara campuran (25.7\%), dipecahkan kepada empat cara iaitu campuran antara serah hak dan faraid, serah hak dan sama rata, faraid dan sama rata dan yang terakhir ialah campuran antara faraid, serah hak dan sama rata.

Hasil tinjauan kes terhadap mekanisme campuran antara serah hak dan faraid, didapati hanya terdapat 1 kes (0.144\%) sahaja sejak lima tahun kebelakangan. Untuk campuran antara faraid dan sama rata pula, hanya 2 kes $(0.3 \%)$ sahaja yang direkodkan. Campuran antara serah hak dan sama rata pula mencatatkan sebanyak 165 kes (23.81\%), manakala campuran antara faraid, serah hak dan sama rata pula merekodkan sebanyak 10 kes (1.44\%).

Rajah 5: Peratusan Mekanisme Campuran Terhadap Tuntutan Tanah Waris Bagi Tahun 2010-2014

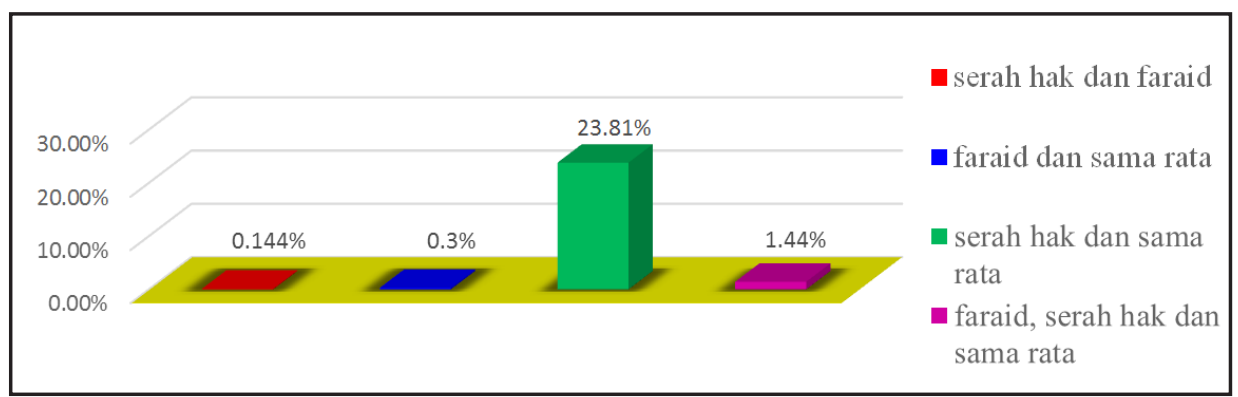

Sumber: Hasil Penyelidikan Penulis.

Jika diambil kira peratusan yang didapati melalui mekanisme campuran antara serah hak dan sama rata (23.81\%), hanya sejumlah 53 kes $(7.65 \%)$ sahaja yang menentukan bahawa mereka bersetuju untuk membahagikan harta tersebut secara serah hak dan sama rata iaitu dengan mengisi keduadua borang penyerahan dan penerimaan dan juga borang berbahagi sama rata. Manakala selebihnya 112 kes (16.16\%) tidak menyatakan atau menentukan untuk berbahagi sama rata iaitu dengan hanya mengisikan borang penyerahan dan penerimaan sahaja.

Menurut undang-undang pusaka Islam, mana-mana waris yang menarik diri dari menerima harta pusaka dengan suka rela tanpa apa-apa balasan, ahli waris yang menarik diri itu hendaklah menentukan sama ada memberikan haknya kepada seseorang atau kepada beberapa orang ataupun kepada semua ahli waris. Sekiranya penyerahan itu dibuat kepada beberapa orang atau kepada semua waris, ahli waris yang menarik diri itu juga hendaklah menentukan sama ada bahagiannya itu dibahagikan sama banyak, atau mengikut kadar faraid atau apa-apa corak pembahagian yang dikehendakinya. 
Seandainya waris yang menarik diri itu tidak menentukan kaedah pembahagian, maka bahagian ahli waris yang menarik diri itu hendaklah dibahagikan sama banyak kepada ahli waris yang menerima (Abdul Kadir Ismail, 1993: 333).

Perkara ini menurut pandangan penulis, hendaklah diambil perhatian lebih oleh Unit Waris Mahkamah Tinggi Syariah. Ini adalah kerana menurut amalan yang ada pada masa ini, mana-mana waris yang menolak bahagian dan menyerahkannya kepada waris lain, mereka tidak menetapkan corak pembahagian sepertimana yang dikehendaki syarak. Oleh itu, demi untuk menyelaraskan bentuk pembahagian secara muafakat selaras dengan kehendak syarak, maka adalah disarankan agar Unit Waris meminta kepastian daripada setiap ahli waris yang menolak haknya untuk menetapkan sendiri corak pembahagian yang diinginkan.

Di samping itu, berdasarkan pengamatan penulis sendiri, pembahagian harta tak alih yang berupa tanah, pada kebiasaannya menggunakan kaedah persetujuan bersama (muafakat) dengan menyerahkan tanah tersebut kepada salah seorang ahli waris si mati jika tanah yang dimiliki itu sempit dan tidak mempunyai keluasan yang banyak. Manakala bagi tanah waris yang banyak (berkeping-keping) atau mempunyai keluasan yang besar, maka harta tersebut selalunya akan dibahagi mengikut kadar sama rata antara ahli waris.

Menurut Pendaftar Mahkamah Tinggi Syariah, pemilihan kaedah muafakat ini didorong atas dasar utamanya iaitu untuk memudahkan proses tuntutan. Ini adalah kerana sikap ahli waris yang gemar memilih jalan mudah dan cepat dalam menyelesaikan pembahagian harta pusaka. Selain daripada itu, pemilihan kaedah muafakat ini juga dipengaruhi oleh perasaan kasih sayang dan penghargaan ahli waris kepada ahli waris yang lain terutama pada anakanak. ${ }^{4}$ Ringkasnya, jadual dibawah memperlihatkan mekanisme aplikasi kaedah muafakat dalam agihan harta pusaka orang Islam Daerah Brunei Muara:

4 Kartini Abdullah (Pendaftar Mahkamah Tinggi Syariah Negara Brunei Darussalam), dalam temu bual dengan penulis, pada 16 Jun 2015. 
Jadual 6: Mekanisme Kaedah Muafakat Yang Diamalkan Oleh Masyarakat Islam Daerah Brunei Muara

\begin{tabular}{clcl}
\hline Bil. & \multicolumn{2}{c}{ Mekanisme Kaedah Muafakat Yang Diaplikasikan } \\
\hline 1 & Serah hak & & \\
2 & Sama rata & i & faraid + serah hak \\
& & ii & faraid + sama rata \\
3 & Campuran & iii & serah hak + sama rata \\
& & iv & faraid + serah hak + sama rata \\
\hline
\end{tabular}

Sumber: Hasil Penyelidikan Penulis.

\section{Analisis Kaedah Pembahagian Ke Atas Tukar Milik Perumahan}

Perumahan yang dimaksudkan ialah bagi mereka yang mengikuti Rancangan Perumahan Negara (RPN) dan Skim Tanah Kurnia Rakyat Jati (STKRJ) atau lain-lain skim di bawah kelolaan Jabatan Kemajaun Perubmahan. Bagi tempoh lima tahun kebelakangan dari 2010-2014, hanya terdapat 60 kes yang didaftarkan untuk permohonan tukar milik perumahan di Unit Waris Mahkamah Tinggi Syariah bagi permohonan Daerah Brunei Muara. Kesemua kes diambil untuk dianalisis.

Dalam melaksanakan pembahagian tuntutan tukar milik perumahan, setiap ahli waris tidak berhak memilih kaedah pembahagian secara bebas. Ini memandangkan terdapat sekatan undang-undang yang telah ditetapkan oleh Jabatan Kemajuan Perumahan yang menghalang sebarang penurunan hak milik perumahan kepada lebih daripada seorang. Keadaan ini amat berbeza dengan urusan pembahagian tanah waris yang mana ahli waris diberi kebebasan sepenuhnya untuk memilih kaedah yang dipersetujui dengan penuh kerelaan tanpa dipengaruhi oleh mana-mana pihak.

Tukar milik perumahan hanya akan diserahkan kepada seorang ahli waris mengikut senarai nama yang terkandung dalam sijil faraid yang telah dikeluarkan oleh Unit Waris Mahkamah Tinggi Syariah dengan mengambil kira syarat kelayakan yang telah ditetapkan oleh Jabatan Kemajuan Perumahan. Penilaian tersebut hanya akan dibuat oleh Jabatan Kemajuan Perumahan sendiri. Syarat-syarat serta kelayakan yang telah ditetapkan adalah seperti berikut:

a) Pengambil alih hendaklah terdiri dari rakyat Brunei, berumur $18 \mathrm{ke}$ atas, mempunyai pekerjaan dan berpendapatan tetap sebaik-sebaiknya berkhidmat dengan kerajaan. 
b) Jika pengambil alih rumah Skim Tanah Kurnia Rakyat Jati hendaklah terdiri dari Rakyat Jati Mutlak mengikut Bab 4(1) (a) Undang-Undang Taraf Kebangsaan Brunei 1961.

c) Pengambil alih terdiri dari ahli waris terdekat (suami/isteri, anak, ibu/bapa).

d) Pengambil alih suami/isteri tidak memiliki tanah bergeran.

e) Pengambil alih suami/isteri akan dikenakan sekatan syarat tidak lagi berhak untuk mengikuti mana-mana Rancangan Perumahan Negara, Skim Tanah Kurnia Rakyat Jati, Skim Kurnia Tanah, Skim Penggeranan Tanah dan Skim Penempatan Semula serta mana-mana Skim Pengurniaan Tanah dan Rumah dan Skim-Skim lain yang diberi.

f) Rumah yang berhak diambil alih tidak mempunyai bayaran tunggakan.

g) Bayaran rumah akan disambung oleh penerima bayaran.

h) Telahpun menerima perkenan untuk mengikuti Rancangan Perumahan Negara/Skim Tanah Kurnia Rakyat Jati.

i) Terdapat persetujuan daripada ke semua ahli waris yang telah ditetapkan oleh Mahkamah Tinggi Syariah.

j) Syarat-syarat adalah tertakluk kepada sebarang perubahan dari masa ke semasa.

Sekiranya setiap ahli waris telah bersetuju untuk menyerahkan rumah tersebut kepada salah seorang ahli waris yang dikira berkelayakan untuk menerima rumah tersebut, maka mereka hanya perlu mengisi borang penyerahan dan penerimaan dan borang tersebut hendaklah ditandatangani oleh setiap ahli waris tanda persetujuan mereka.

Seandainya setiap ahli waris yang tersenarai dalam sijil faraid atau ahli waris yang diturunkan milik kepadanya itu didapati tidak menepati syarat yang dikehendaki, maka Jabatan Kemajuan Perumahan berhak untuk mempertimbangkan permohonan mereka di luar senarai ahli waris, tertakluk kepada peraturan dan syarat yang telah ditetapkan.

Walau bagaimanapun, menerusi pengamatan penulis, meskipun tuntutan tukar milik perumahan dikawal oleh undang-undang yang telah ditetapkan oleh Jabatan Kemajuan Perumahan, pindah milik perumahan kepada seorang ahli waris dilihat tidak melanggar ketentuan syara' bahkan ianya menepati ciri-ciri al-takhāruj yang dianjurkan dalam Islam. Ini kerana memandangkan proses tuntutan tukar milik perumahan yang dilaksanakan di Unit Waris ini menghendaki persetujuan daripada setiap ahli waris yang tersenarai dalam sijil faraid. Tanpa persetujuan daripada setiap ahli waris, pastinya proses tukar milik akan tergendala dan tidak dapat diproses.

Meskipun menurut Islam suatu ganti rugi itu boleh dituntut akibat melepaskan hak kepada ahli waris lain, akan tetapi penulis tidak menemukan 
satu permohonan pun yang mengemukakan ganti rugi bagi permohonan tukar milik perumahan. Keadaan ini sama seperti tuntutan tanah waris. Besar kemungkinan, masyarakat setempat tidak mengetahui berkenaan dengan pampasan yang dibolehkan ini.

\section{KESIMPULAN}

Pada hemat penulis, kaedah muafakat yang dipraktikkan oleh masyarakat Islam Daerah Brunei Muara terhadap harta tak alih adalah menepati kaedah al-takhāruj yang dianjurkan Islam kerana ianya dilaksanakan mengikut kerelaan tanpa dipengaruhi oleh sebarang unsur paksaan dan didasari dengan konsep redha meredhai. Namun begitu, setiap ahli waris yang terlibat dan masyarakat lain umumnya, hendaklah mengetahui terlebih dahulu hak mereka terhadap pusaka sebelum membuat sebarang penyerahan supaya tidak berlaku sebarang helah dan penyelewengan daripada waris yang menerima tolakan untuk mendapatkan bahagian waris-waris lain tanpa mereka ketahui bahagian sebenar yang sepatutnya mereka perolehi.

Melalui kaedah muafakat atau kaedah takhāruj dalam urusan pembahagian harta pusaka di daerah ini, ia ternyata memberi manfaat kepada setiap ahli waris. Kaedah ini dilihat mampu memudahkan urusan pembahagian pusaka, bahkan harta tersebut dapat diusaha dan dimajukan dengan segera.

Isu mengenai penentuan cara harta tersebut dibahagikan oleh waris yang menarik diri haruslah diambil perhatian dan diusahakan untuk mendapatkan kepastian yang lebih teliti daripada waris yang menarik diri. Ini bertujuan agar amalan yang dilakukan benar-benar menepati kriteria yang terkandung dalam konsep al-takhāruj dan selaras sepenuhnya sepertimana yang dianjurkan Islam.

Manakala berkenaan dengan ganti rugi atau pampasan yang dianjurkan dalam kaedah al-takhāruj pula, para cendikiawan Islam telah berpendapat bahawa ianya bukanlah sesuatu yang bersifat wajib. Namun, ianya akan bertukar menjadi suatu kewajipan apabila diminta oleh ahli waris yang menyerahkan bahagiannya kepada waris yang lain (Abdul Shakor Borhan, 1999: 192). Walau bagaimanapun, berdasarkan hasil analisis yang dijalankan, tiada satu pun permohonan yang mengemukakan pampasan atau ganti rugi terhadap harta yang diserahkan atau dilepaskan kepada ahli waris lain sama ada tuntutan tanah waris mahupun tukar milik perumahan. Dalam perkara ini, penulis berpandangan bahawa terdapat dua kemungkinan.

Pertama, mungkin ada di antara mereka yang menerima ganti rugi tetapi perlaksanaannya tidak dimuatkan ke dalam rekod fail mahkamah. Dalam erti 
kata lain melalui rundingan luar. Kedua, besar kemungkinan masyarakat Islam setempat tidak mengetahui perihal pampasan yang dianjurkan Islam akibat daripada kurangnya ilmu pengetahuan atau pendedahan mengenai perkara tersebut.

Oleh yang demikian, dalam melaksanakan kaedah pembahagian harta pusaka tak alih orang Islam di Daerah Brunei Muara, terdapat beberapa aspek yang perlu diberi penekanan dan perhatian terutama dari sudut penyebaran info maklumat dan penerangan lanjutan agar kaedah pembahagian yang digunakan benar-benar memberikan kesan positif kepada seluruh masyarakat Islam setempat. Suatu gagasan dan langkah yang progresif perlu dilakukan demi memperkenalkan dan menyebarluaskan lagi maklumat berkenaan kaedah muafakat ini.

\section{RUJUKAN}

Abdul Kadir Ismail (1993). Sistem Pusaka Islam. Kuala Lumpur: Yayasan Dakwah Islamiah Malaysia.

Abdul Rashid Hj. Abdul Latif (1997). Undang-undang Pusaka dalam Islam: Suatu Kajian Perbandingan, cet. ke-3. Kuala Lumpur: Al-Hidayah Publisher.

Abdul Shakor Borhan (1999). “Amalan Pembahagian Harta Pusaka OrangOrang Islam di Daerah Muar, Johor.” Tesis Sarjana, Universiti Malaya, Kuala Lumpur.

Ahmad Hidayat Buang (2007). "Prinsip dan Pentadbiran Pusaka" dalam Undang-Undang Islam di Malaysia: Prinsip \& Amalan, ed. Ahmad Hidayat Buang. Kuala Lumpur: Penerbit Universiti Malaya.

Mohd Zamro Muda \& Mohd. Ridzuan Awang (2006). Undang-Undang Pusaka Islam: Pelaksanaannya di Malaysia. Bangi: Jabatan Syariah, Fakulti Pengajian Islam, UKM.

Wan Najmiah Wan Mohd Ali \& Md. Yazid Ahmad (2013). "Mekanisme Aplikasi Takharuj dalam Pembahagian Harta Pusaka Kecil di Kuala Terengganu," Islamiyyat.

\section{Statut}

Undang-Undang Brunei, Akta Probet dan Pentadbiran 1984, Penggal 11.

Undang-Undang Brunei, Akta Mahkamah-Mahkamah Syariah 2005, Penggal 184. 


\section{Temu bual}

Kartini Abdullah (Pendaftar, Mahkamah Tinggi Syariah Negara Brunei Darussalam), dalam temu bual dengan penulis, pada 16 Jun 2015. 
Journal of Shariah Law Research (JSLR) 